\title{
Long-term voluntary exercise, representing habitual exercise, lowers visceral fat and alters plasma amino acid levels in mice
}

\author{
Haruko Takeshita $\cdot$ Masahisa Horiuchi • \\ Kimiko Izumo • Hiroaki Kawaguchi • \\ Emi Arimura $\cdot$ Kohji Aoyama $\cdot$ Toru Takeuchi
}

Received: 8 July 2011/Accepted: 12 October 2011 / Published online: 4 November 2011

(c) The Japanese Society for Hygiene 2011

\begin{abstract}
Objectives To determine the impact of long-term voluntary exercise, representing habitual exercise for the prevention of lifestyle-related diseases, on glucose, lipid, and amino acid metabolism in mice.

Methods Twenty-four mice aged 6 weeks were divided into three groups. Two groups (16 mice) were housed individually in either cages equipped with a running wheel (8 mice, exercising, Ex-mice) or without (8 mice, sedentary, Se-mice) for 24 weeks. The remaining group ( 8 mice) was sacrificed at 6 weeks of age. Biomarkers related to glucose, lipid, and amino acid metabolism were examined.
\end{abstract}

H. Takeshita · M. Horiuchi $(\bowtie) \cdot$ K. Izumo - E. Arimura ·

K. Aoyama · T. Takeuchi

Department of Environmental Medicine, Graduate School of Medical and Dental Sciences, Kagoshima University,

8-35-1 Sakuragaoka, Kagoshima 890-8544, Japan

e-mail: masakun@m.kufm.kagoshima-u.ac.jp

H. Takeshita

Department of Nutrition, Faculty of Nursing and Nutrition,

Kagoshima Immaculate Heart University,

Kagoshima 895-0011, Japan

Present Address:

H. Takeshita

Department of Economics Education, Faculty of Education, Shizuoka University, 836 Ohya, Suruga-ku,

Shizuoka 422-8529, Japan

H. Kawaguchi

Department of Veterinary Pathology, Faculty of Agriculture,

Kagoshima University, Kagoshima 890-0065, Japan

E. Arimura

Department of Life and Environmental Science,

Kagoshima Prefectural College, Kagoshima 890-0005, Japan
Results Ex-mice ran voluntarily, predominantly in the dark. The distance per day peaked at 4 weeks and then decreased until 12 weeks to around the level seen at the beginning of the experimental period, and was maintained at $4.9 \pm 0.2 \mathrm{~km} /$ day from 12 to 24 weeks. Ex-mice showed a similar adrenal weight and vitamin $\mathrm{C}$ content to Se-mice but had a significantly lower body weight and higher food intake. Ex-mice also showed a higher skeletal muscle weight, a lower white adipose tissue and liver weight, associated with lower plasma leptin and insulin-like growth factor-1 levels, and a lower hepatic triglyceride content. Analysis of plasma amino acids showed that Ex-mice had significantly higher phenylalanine, tyrosine, and glutamine levels, resulting in a significantly lower Fischer's ratio.

Conclusions We present an animal model of long-term voluntary exercise under low stress. Findings related to the effects of long-term voluntary exercise on lipid, and amino acid metabolism in our mouse model indicate that such an exercise regimen may affect pathophysiological states related to appetite and behavior.

Keywords Aromatic amino acids · Energy expenditure . Food intake · Glutamine · Human health

\section{Introduction}

Epidemiological studies have shown that exercise can improve the mean life span, presumably by reducing the mortality risk from lifestyle-related diseases, including cardiovascular disease, stroke, type 2 diabetes, and certain cancers $[1,2]$. Moreover, sedentary behavior is an important risk factor for chronic disease morbidity and mortality with aging [3]. To understand how exercise affects the mortality risk from lifestyle-related diseases, the impact of 
exercise on several biological markers related to glucose and lipid metabolisms has been examined in humans [4-7]. Different forms of exercise, aerobic or anaerobic, voluntary or forced, and differences in the manner, duration, and amount can be expected to have different effects on biological markers in human and rodent models [4-9]. For the prevention of lifestyle-related diseases, such as obesity and diabetes, the Centers for Disease Control and Prevention and the American College of Sports Medicine have jointly published recommendations that adults should engage in at least $30 \mathrm{~min}$ of moderate physical activity (e.g., brisk walking) on most, and preferably all, days of the week $[3,10]$; therefore, the impact of exercise (long-term, moderate physical activity, aerobic, and voluntary), namely, habitual exercise, on biological markers should be analyzed in detail. However, it is difficult to test the effect of longterm habitual exercise on lifestyle-related disease during an individual's life-span in human subjects: such longitudinal studies are difficult in humans. Therefore, at the present time, researchers are obliged to perform experiments on such issues using experimental animals (models).

Experiments have shown that rodents, mainly rats, in cages equipped with a running wheel run for long periods [11-15] and have a decreased body weight gain. A reduction of visceral fat has also been reported in such rats $[16,17]$. These observations are significant in terms of our understanding of the impact of exercise; however, the observation periods (4-8 weeks), which are equivalent to 2-4 years in humans, may have been insufficient to elucidate the impact of habitual exercise $[18,19]$. Female A/J mice have about a 2-year mean life-span [20]; thus, 24 weeks is equivalent to one-fourth of their life-span. In the study reported here, we initiated the experiment at 6 weeks of age, which represents the onset of puberty in mice [21], and continued the study until 30 weeks of age. As such, the experimental period may correspond to adolescence and late middle age in humans.

There have also been several reports on the composition and content of amino acids in the blood of rodents undergoing forced exercise [22, 23]; however, to date, a similar analysis has not been examined in rodents performing longterm and voluntary exercise. We therefore examined the composition and levels of amino acids in the blood of rodents performing long-term voluntary exercise. A number of the amino acids found in the blood, including tyrosine (Tyr), phenylalanine (Phe), and tryptophan, play important roles as precursors of neurotransmitters related to activity in the central nervous system [24, 25]. In a previous report, the possibility that moderate physical activity can reduce symptoms of anxiety and depression was highlighted [10]. Given this finding, it would appear to be important to evaluate the composition and levels of blood amino acids.
In the study reported here, we attempted to establish an animal model to elucidate the impact of 6 months of voluntary exercise by a human using female $\mathrm{A} / \mathrm{J}$ mice, which use a running wheel more readily than other strains and male A/J mice [26, 27]. In this model, we examined several parameters: body composition, food intake, weights of various organs, hormone levels, glucose, lipid, and amino acid concentrations, and gene expression levels in adipose tissue and the liver.

\section{Materials and methods}

Animals

Female A/J mice $(n=24)$ aged 5 weeks were obtained from Japan SLC (Shizuoka, Japan). Female mice were used for the study because they run farther and faster than male A/J mice [26, 27]. The mice were kept under controlled conditions, at a constant room temperature of $22 \pm 2{ }^{\circ} \mathrm{C}$, and at $12 \mathrm{~h}$ of illumination (0700-1900 hours). The mice were allowed ad libitum access to food $(14.4 \mathrm{~kJ} / \mathrm{g}, \mathrm{CE}-2$; CLEA, Tokyo, Japan) and water. After an acclimation period of 1 week ( 6 weeks of age; designated as 0 weeks for exercise or sedentary mice), the mice were randomly divided into two groups: sedentary mice (Se-mice, $n=8$ ) and exercising mice (Ex-mice, $n=8$ ). As shown in Fig. 1a, Ex-mice were kept individually in a cage equipped with a running wheel (diameter $0.22 \mathrm{~m}$; the equipment was constructed in collaboration with Mr. Y Okada of Natsume Seisakusho Co. Ltd., Tokyo, Japan). Se-mice were kept individually in a cage with a steel plate providing the same living area as the cage for exercise. The cages for Ex- and Se-mice were changed for cleaning once a week. Food intake amount and body weight were measured weekly between 0800 and 1000 hours until 30 weeks of age (24 weeks after initiation of exercise). The remaining eight mice were sacrificed at 6 weeks of age to obtain the baseline (pre-exercise) data. As a pilot experiment, we obtained several female $\mathrm{A} / \mathrm{J}$ mice at 5 weeks of age. The mice were kept individually in cages equipped for exercise, as shown in Fig. 1b; the remaining mice were kept individually in cages without a running wheel. The cages were made entirely of steel. Some mice kept in the cages were sacrificed due to a severe decrease in body weight. From these results, we performed all experiments in plastic cages, with the bottom of the living area covered with wood chips, as shown in Fig. 1a.

This study was approved by the Ethics Committee for Animal Experimentation at Kagoshima University, which is standardized to the Japanese national guidelines for animal experiments. 
Fig. 1 Apparatus for studying long-term voluntary exercise in mice. Both types of cage were equipped with a running wheel as shown. a Plastic cage composed of a running wheel and living area (standard breeding cage), with the bottom covered with wood chips, b cage made entirely of steel
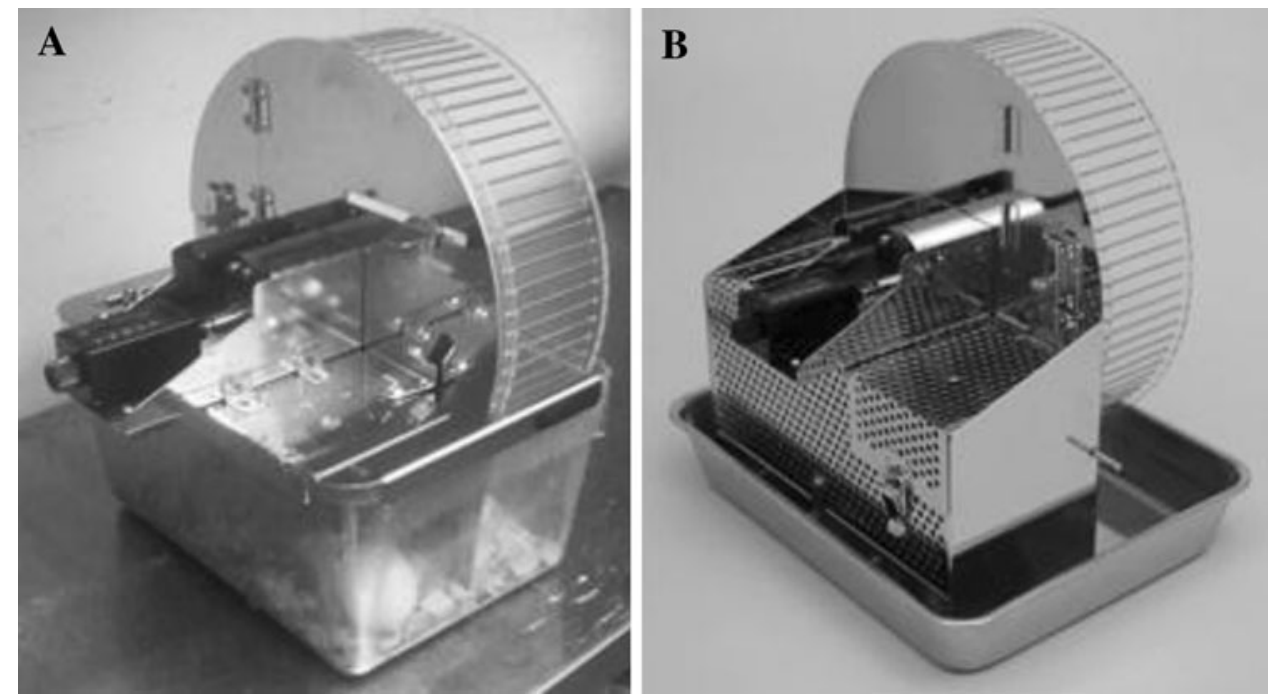

\section{Exercise}

Ex-mice were housed individually and kept in cages equipped with a running wheel. The running distance was calculated by multiplying the circumference $(0.7 \mathrm{~m})$ of the running wheel by the number of rotations recorded on the counter.

\section{Collection of blood and organs}

At 6 or 30 weeks of age, the mice were fasted from 0700 hours on the day scheduled for sacrifice up to 1300 hours when they were anesthetized (pentobarbital $100 \mathrm{mg} / \mathrm{kg}$, intraperitoneal) and sacrificed. Blood $(0.5 \mathrm{ml})$ was drawn from the heart with a syringe containing $10 \mu \mathrm{l}$ of $0.2 \mathrm{~mol} / \mathrm{L}$ EDTA, and organs, including the heart, liver, fat surrounding the ovaries [white adipose tissue (WAT)], adrenal glands, and soleus muscles, were isolated. The organs were rinsed in isotonic saline, weighed, and quickly frozen in liquid nitrogen. The blood was centrifuged at $3,000 \mathrm{rpm}$ for $5 \mathrm{~min}$ for the separation of plasma. The plasma and frozen organs were stored at $-80^{\circ} \mathrm{C}$ until analysis.

\section{Blood chemistry}

Plasma glucose, free fatty acids (FFA), total cholesterol, high density lipoprotein (HDL)-cholesterol, and triglycerides (TG) were measured with the appropriate kits (Wako, Osaka, Japan). Plasma insulin (Morinaga, Kanazawa, Japan), leptin (R\&D Systems, Minneapolis, MN), adiponectin (Ohtsuka Pharmaceutical, Tokyo, Japan), insulin-like growth factor 1 (IGF-1; R\&D Systems), and corticosterone (Assay Designs, Ann Arbor, MI) were measured with the appropriate kits, based on enzyme immunoassays. Plasma amino acid concentrations were determined with a JLC-500 model amino acid analyzer (JEOL, Tokyo, Japan) after deproteinzation with $5 \%(\mathrm{w} / \mathrm{v})$ sulfosalicylic acid.

\section{Lipids in liver}

The frozen liver was weighed and added to lipid extraction solution consisting of methanol-chloroform and then homogenized. The organic phase was transferred to glass tubes, evaporated with nitrogen gas, reconstituted in an isopropanol-Triton X-100 mixture (10\% v/v), and then vortexed [28]. Lipid content was measured with kits (TG E test, Cho-CII test; Wako Pure Chemical, Osaka, Japan).

Vitamin $\mathrm{C}$ in adrenal glands

The frozen adrenal glands were homogenized with 100 volumes of 0.1 mol/L-phosphate buffer ( $\mathrm{pH} 7.4$ ) [29, 30]. One percent of the tissue homogenate was prepared and centrifuged at $12,000 \mathrm{~g}$ for $10 \mathrm{~min}$ at $4^{\circ} \mathrm{C}$. Adrenal vitamin $\mathrm{C}$ levels were determined with an L-ascorbic acid kit (R-Biopharm AG, Darmstadt, Germany).

\section{Real-time PCR for quantification of mRNAs}

Total RNA was isolated from the frozen organs, including WAT and the liver, with TRIzol (Invitrogen, Carlsbad, CA) and treated with DNAase to remove any genomic contamination. First-strand cDNA synthesis was performed using $5 \mu \mathrm{g}$ total RNA and the oligo- $(\mathrm{dT})_{18}$ primer following the manufacturer's instructions (Invitrogen). Real-time quantitative PCR was performed using SYBR Green on a TAKARA detection system (TAKARA, Shiga, Japan) 
Table 1 Sequence of primers for real time-PCR
GAPDH Glyceraldehyde-3-

phosphate dehydrogenase, FAS

Fatty acid synthase, G6PD

glucose-6-phosphate dehydrogenase, $L P L$ lipoprotein lipase, $H S L$ hormone-sensitive lipase, $A T G L$ adipocyte triglyceride lipase, $F A B P 4$ fatty acid-binding protein $4, I G F-1$ insulin-like growth factor 1 ,

Glut2 glucose transporter 2, GK glucokinase, $P E P C K$

phosphoenol pyruvate carboxykinase, $F$ forward primer, $R$ reverse primer

\begin{tabular}{|c|c|c|}
\hline Gene & Gene ID & Sequence \\
\hline GAPDH & 14433 & $\begin{array}{l}\text { F: 5'-ATGGTGAAGGTCGGTGTGAA-3' } \\
\text { R: 5'-GAGTGGAGTCATACTGGAAC-3' }\end{array}$ \\
\hline FAS & 14104 & $\begin{array}{l}\text { F: 5'-TGCTCCCAGCTGCAGGC-3' } \\
\text { R: 5'-GCCCGGTAGCTCTGGGTGTA-3' }\end{array}$ \\
\hline G6PD & 14381 & $\begin{array}{l}\text { F: 5'-TCAAGAGACCTGCATGAGTCAGA-3' } \\
\text { R: 5'-TGGCAAACCTCAGCACCAT-3' }\end{array}$ \\
\hline LPL & 16956 & $\begin{array}{l}\text { F: 5'-CAGCTGGGCCTAACTTTGAG-3' } \\
\text { R: 5'-AATCACACGGATGGCTTCTC-3' }\end{array}$ \\
\hline HSL & 16890 & $\begin{array}{l}\text { F: 5'-GCACCTTGTGGCTTGCGCT -3' } \\
\text { R: 5'-CTTTCAGCGTCACCGGCTG-3' }\end{array}$ \\
\hline ATGL & 66853 & $\begin{array}{l}\text { F: 5'-TGCCTTCCAGACTGTCTGAG -3' } \\
\text { R: 5'-CGTACCCAGTTGGGTAGGG-3' }\end{array}$ \\
\hline Adipsin & 11537 & $\begin{array}{l}\text { F: 5'-CAACCGCAGGGACACTTGCA-3' } \\
\text { R: 5'-CTGAGCCACGTGTCTCTGGT-3' }\end{array}$ \\
\hline FABP4 & 11770 & $\begin{array}{l}\text { F: 5'-GATGGTGACAAGCTGGTGGT-3' } \\
\text { R: 5'-CAGGCCTCTTCCTTTGGCTC-3' }\end{array}$ \\
\hline Leptin & 16846 & $\begin{array}{l}\text { F: 5'-CTGTGGCTTTGGTCCTATCT-3' } \\
\text { R: 5'-TGATAGACTGCCAGAGTCTG-3' }\end{array}$ \\
\hline Adiponectin & 11450 & $\begin{array}{l}\text { F: 5'-TCCGGGACTCTACTACTTCTCTTACCAC-3' } \\
\text { R: } 5^{\prime} \text {-GTCCCCATCCCCATACACCTG-3' }\end{array}$ \\
\hline IGF-1 & 16000 & $\begin{array}{l}\text { F: 5'-CTGGACCAGAGACCCTTTGC-3' } \\
\text { R: 5'-AGAGCGGGCTGCTTTTGTAG-3' }\end{array}$ \\
\hline Glut2 & 20526 & $\begin{array}{l}\text { F: 5'-GCCCTCTGCTTCCAGTACAT-3' } \\
\text { R: 5'-GTTCCTCGGTTTTAGGCAGG-3' }\end{array}$ \\
\hline GK & 103988 & $\begin{array}{l}\text { F: 5'-TATGAAGACCGCCAATGTGA-3' } \\
\text { R: 5'-TTTCCGCCAATGATCTTTTC-3' }\end{array}$ \\
\hline PEPCK & 18534 & $\begin{array}{l}\text { F: 5'-CCACAGCTGCTGCACAACAC-3' } \\
\text { R: 5'-GAAGGGTCGCATGGCAAA-3' }\end{array}$ \\
\hline
\end{tabular}

under the standard conditions recommended by the manufacturer. We used the mouse glyceraldehyde-3-phosphate dehydrogenase (GAPDH) gene as an internal control for all samples. All expression data were normalized to the level of GAPDH expression from individual samples. The primers used are shown in Table 1.

Statistical analysis

For all experiments, the unpaired $t$ test or two-way analysis of variance (ANOVA) was applied as appropriate to identify significant differences between groups, using Ekuseru-Tokei 2008 software (SSRI Co., Tokyo, Japan), with $p<0.05$ as the criterion. When a significant difference was shown by two-way ANOVA (exercise and time) for repeated measurements, a post-hoc analysis was performed using the Tukey-Kramer test to determine specific differences (Fig. 2). Values are presented as the mean \pm standard error (SE).

\section{Results}

Running distance, body weight, and food intake

As shown in Fig. 2a, the running distance increased until 10 weeks of age $(7.2 \pm 0.4 \mathrm{~km} /$ day between weeks 1 and 4$)$ and gradually decreased until week 12 ; thereafter, the average distance between 12 and 24 weeks was $4.9 \pm 0.2 \mathrm{~km} /$ day. Running was observed principally during the dark phase (at 16 weeks: $5.29 \pm 0.79$ in the dark phase vs. $0.13 \pm$ $0.09 \mathrm{~km} / 12 \mathrm{~h}$ in the light phase; $p<0.05$ ). As shown in Fig. 2b, Ex-mice had a lower body weight than Se-mice during the entire experimental/exercise period. Corresponding to the running activity as shown in Fig. 2a, Ex-mice had a significantly higher food intake than Se-mice from weeks 1 to 16 (two-way ANOVA; Fig. 2c; however, there were no significant differences in food intake between $\mathrm{Ex}$ - and Se-mice from weeks 16 to 24 . Over the entire 24 weeks of the experiment, Ex-mice had a significantly higher calorie intake 

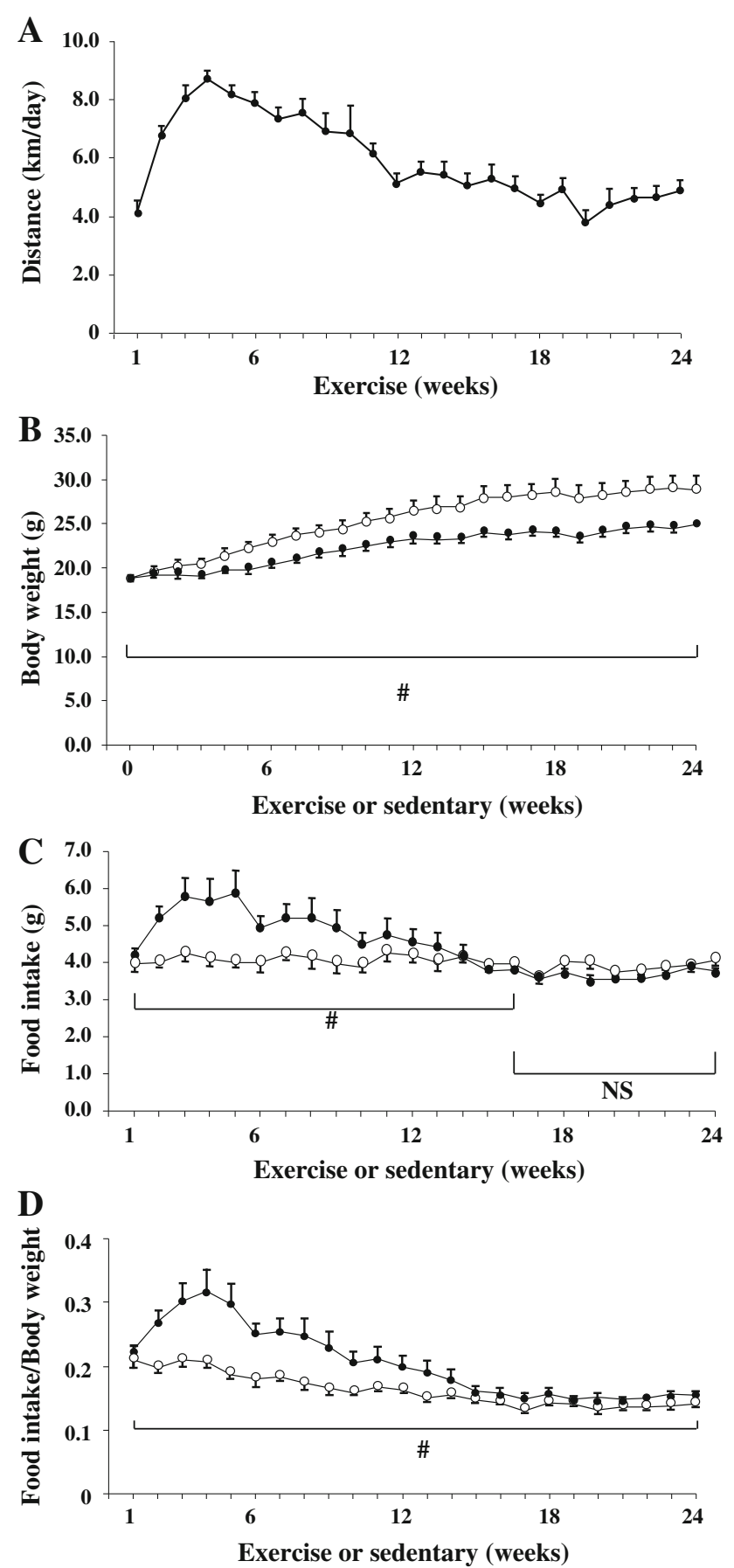

Fig. 2 Voluntary activity, body weight, and food intake during the experimental period. Voluntary activity is expressed as the weekly running distance of the mice in cages equipped with a running wheel (Ex-mice; $n=8 ; \mathbf{a})$. Body weight (b), food intake (c), and ratio of food intake/body weight (d) of Ex-mice (closed circle) and mice whose cages were not equipped with a running wheel (Se-mice; (open circle, $n=8)$ are presented. Data are expressed as the mean \pm standard error (SE). b-d Statistical analysis by two-way analysis of variance (ANOVA; exercise and time) for repeated measurements. Statistical significance ${ }^{\#} p<0.05$ in the indicated area, NS not significant than Se-mice $(745 \pm 50$ vs. $582 \pm 21 \mathrm{~kJ} ; p<0.05)$. To evaluate the influence of body weight on food intake, the latter was divided by body weight. As shown in Fig. 2d, Exmice had a significantly higher food intake/body weight than Se-mice during the entire period, indicating increased energy consumption through the use of the running wheel.

Stress parameters

As shown in Table 2, there were no significant differences in terms of weight or vitamin $\mathrm{C}$ content of the adrenal glands between Ex-mice and Se-mice. Additionally, Exmice and Se-mice had a similar plasma corticosterone level $(146 \pm 16$ vs. $158 \pm 24 \mu \mathrm{g} / \mathrm{L} ; p>0.10)$.

Organ weights and lipids contents in liver

As shown in Table 2, Ex-mice had a significantly lower liver and WAT weight than Se-mice. The soleus muscles as red muscle were heavier in Ex-mice than in Se-mice. There were no significant differences in the weight of the heart between Ex- and Se-mice, suggesting no severe load on the cardiovascular system. The ratio of the organ weight divided by body weight is also shown in Table 2. The significance of the ratios in WAT, soleus muscle, heart, and adrenal gland between Se- and Ex-mice is similar to that of the respective raw value. Compared with the ratio of the organ weight divided by body weight at 6 weeks of age, Se-mice had a significantly higher value in WAT, and significantly lower values in the soleus muscle, heart, and adrenal gland. On the other hand, Ex-mice showed significantly lower values in the liver and adrenal gland than 6-week-old mice. As shown, there were no significant differences in the ratio of WAT weight/body weight between mice at 6 weeks and Ex-mice at 30 weeks of age. In terms of lipids in the liver, Ex-mice had significantly lower TG levels, but not cholesterol levels, than Se-mice.

\section{Blood analyses}

As shown in Table 3, several parameters associated with glucose and lipid metabolism in blood were examined. There were no significant differences in glucose, TG, total cholesterol, or HDL-cholesterol among 6-week-old mice and Ex- and Se-mice. Ex-mice had a lower FFA than Semice, but the difference was not significant $(p=0.072)$. Ex-mice showed significantly lower leptin and IGF-1 levels than Se-mice and, in addition, showed significantly lower insulin and leptin levels than 6-week-old mice. As shown in Table 4, Ex-mice had significantly higher glutamine, Phe, and Tyr levels than Se-mice. The Fischer's 
Table 2 Weights of organs, composition of lipids in the liver, and vitamin C level in adrenal glands

\begin{tabular}{|c|c|c|c|}
\hline \multirow[t]{2}{*}{ Variable } & \multicolumn{3}{|l|}{ Group } \\
\hline & 6 weeks $(n=8)$ & Se-mice $(n=8)$ & Ex-mice $(n=8)$ \\
\hline Body weight (g) & $17.9 \pm 0.2$ & $28.8 \pm 1.5$ aа & $25.0 \pm 0.4$ aa,b \\
\hline Liver $(g)$ & $0.86 \pm 0.02(4.8)$ & $1.29 \pm 0.06$ aa $(4.6)$ & $1.14 \pm 0.04$ aa,b (4.5 a) \\
\hline WAT (g) & $0.26 \pm 0.01(1.4)$ & $0.90 \pm 0.19$ aа (3.1 aа) & $0.44 \pm 0.06 \mathrm{a}, \mathrm{bb}(1.7 \mathrm{~b})$ \\
\hline Soleus muscles (mg) & $13.0 \pm 0.5(0.07)$ & $14.9 \pm 0.4$ aa $(0.05$ aa $)$ & $17.8 \pm 0.7 \mathrm{aa}, \mathrm{bb}(0.07 \mathrm{bb})$ \\
\hline Heart (mg) & $85.0 \pm 1.6(0.47)$ & $110.0 \pm 1.2$ aa $(0.40 \mathrm{aa})$ & $116.5 \pm 2.3$ aa $(0.47)$ \\
\hline Adrenal glands (mg) & $9.8 \pm 0.7(0.05)$ & $9.1 \pm 0.4(0.03$ aa $)$ & $8.7 \pm 0.8(0.03$ aa $)$ \\
\hline \multicolumn{4}{|l|}{ Lipids in liver ${ }^{\mathrm{a}}$} \\
\hline TG (mg/g) & & $6.30 \pm 0.95$ & $3.97 \pm 0.44 \mathrm{~b}$ \\
\hline Cholesterol (mg/g) & & $1.46 \pm 0.36$ & $1.30 \pm 0.43$ \\
\hline Vitamin $\mathrm{C}$ in adrenal glands ${ }^{\mathrm{a}}(\mathrm{mg} / \mathrm{g})$ & & $0.47 \pm 0.03$ & $0.54 \pm 0.02$ \\
\hline
\end{tabular}

Values followed by lowercase 'a' and 'aa' are significantly different from mice at 6 weeks at $p<0.05$ and $p<0.01$, respectively; values followed by lowercase ' $\mathrm{b}$ ' and 'bb' are significantly different from Se-mice at $p<0.05$ and $p<0.01$, respectively

Values are presented as the mean \pm standard error (SE), with the value in parenthesis denoting distribution (\%) of the organ weight to the body weight. Values were analyzed by Student's $t$ test

WAT White adipose tissue, $T G$ triglycerides, Ex-mice mice housed in cages equipped with a running wheel (exercise), Se-mice mice housed in cages without a running wheel (sedentary)

${ }^{\text {a }}$ Contents of lipids and vitamin $\mathrm{C}$ are expressed per $1 \mathrm{~g}$ of the tissue wet weight

Table 3 Values of compounds related to glucose and lipid metabolism in the blood

\begin{tabular}{|c|c|c|c|}
\hline \multirow[t]{2}{*}{ Compounds } & \multicolumn{3}{|l|}{ Group } \\
\hline & $\begin{array}{l}6 \text { weeks } \\
(n=8)\end{array}$ & $\begin{array}{l}\text { Se-mice } \\
(n=8)\end{array}$ & $\begin{array}{l}\text { Ex-mice } \\
(n=8)\end{array}$ \\
\hline Glucose $(\mathrm{g} / \mathrm{L})$ & $2.13 \pm 0.25$ & $2.62 \pm 0.31$ & $2.65 \pm 0.34$ \\
\hline FFA (mEq/L) & $0.30 \pm 0.02$ & $0.34 \pm 0.02$ & $0.30 \pm 0.01$ \\
\hline TG (mg/L) & $501 \pm 75$ & $694 \pm 78$ & $669 \pm 126$ \\
\hline $\begin{array}{l}\text { Total cholesterol } \\
(\mathrm{mg} / \mathrm{L})\end{array}$ & $610 \pm 34$ & $648 \pm 34$ & $655 \pm 27$ \\
\hline $\begin{array}{l}\text { HDL-cholesterol } \\
(\mathrm{mg} / \mathrm{L})\end{array}$ & $333 \pm 23$ & $338 \pm 24$ & $329 \pm 27$ \\
\hline Insulin $(\mu \mathrm{g} / \mathrm{L})$ & $0.49 \pm 0.08$ & $0.32 \pm 0.03$ & $0.31 \pm 0.02 \mathrm{a}$ \\
\hline Leptin $(\mu \mathrm{g} / \mathrm{L})$ & $5.8 \pm 0.8$ & $9.1 \pm 2.8$ & $2.9 \pm 0.9 \mathrm{a}, \mathrm{b}$ \\
\hline IGF-1 $(\mu \mathrm{g} / \mathrm{L})$ & $222.5 \pm 14.9$ & $241.6 \pm 3.4$ & 223. $0 \pm 6.8 \mathrm{~b}$ \\
\hline
\end{tabular}

Values followed by lowercase 'a' are significantly different from mice at 6 weeks at $p<0.05$; values followed by lowercase 'b' are significantly different from Se-mice at $p<0.05$

Values are expressed as the mean \pm SE. Values were analyzed by Student's $t$ test

FFA Fee fatty acids, $T G$ triglycerides, $H D L$ high-density lipoprotein, $I G F-1$ insulin-like growth factor-1

ratio, i.e., $[\mathrm{BCAA}] /[\mathrm{Phe}+\mathrm{Tyr}]$, where $\mathrm{BCAA}$ is the concentration of branched-chain amino acids (leucine, isoleucine, and valine), was significantly lower in Ex-mice than in Se-mice. Ex-mice had a significantly higher total amino acid content than Se-mice. Compared with 6-week-old mice, Ex-mice had significantly higher blood alanine, arginine, asparagine, glutamine, serine, tyrosine, and urea levels, significantly lower blood aspartic acid and methionine levels, and a significantly lower Fischer's ratio. On the other hand, Se-mice had a significantly higher blood urea level, significantly lower blood aspartic acid, lysine, and methionine levels, and a significantly lower Fischer's ratio.

Expression levels of genes related to glucose and lipid metabolism

To elucidate the mechanisms of lower WAT and liver weights in Ex-mice compared with Se-mice, we examined the mRNA levels of the genes related to glucose and lipid metabolism. Fatty acid synthase and glucose-6-phosphate dehydrogenase (G6PD) are related to fatty acid synthesis. Lipoprotein lipase, hormone-sensitive lipase, and adipocyte triglyceride lipase are related to triglycerides and fatty acid degradation. Glucose transporter 2 and glucokinase are related to glucose uptake. Phosphoenol pyruvate carboxykinase is related to gluconeogenesis in the liver. Adipsin and fatty acid-binding protein 4 are adipocyte markers. Leptin and adiponectin are adipocytokines. IGF-1 is thought to function as a growth factor. Among these, leptin in WAT was significantly lower in Ex-mice than in Semice (Fig. 3). 
Table 4 Concentrations of plasma amino acids and urea

Values followed by lowercase 'a' and 'aa' are significantly different from mice at 6 weeks at $p<0.05$ and $p<0.01$.

Values followed by lowercase 'b' are significantly different from Se-mice at $p<0.05$

Values are expressed as the mean \pm SE. Findings were analyzed by Student's $t$ test

${ }^{a}$ Ratio means the quotient of the respective values of Ex-mice divided by the values of $\mathrm{Se}$ mice

b Fischer's ratio means $[\mathrm{BCAA}] /[\mathrm{Phe}+\mathrm{Tyr}]$, in which $[\mathrm{BCAA}]$ is the concentration of branched-chain amino acids (leucine, valine, isoleucine) and $[\mathrm{Phe}+\mathrm{Tyr}]$ is the concentration of phenylalanine and tyrosine

\begin{tabular}{|c|c|c|c|c|}
\hline \multirow{2}{*}{$\begin{array}{l}\text { Plasma amino acids } \\
\text { and urea }(\mu \mathrm{mol} / \mathrm{L})\end{array}$} & \multicolumn{3}{|l|}{ Group } & \multirow[t]{2}{*}{ Ratio $^{a}$} \\
\hline & 6 weeks $(n=8)$ & Se-mice $(n=6)$ & Ex-mice $(n=5)$ & \\
\hline Alanine & $338.9 \pm 37.5$ & $380.3 \pm 41.6$ & $488.6 \pm 32.3$ aа & 1.28 \\
\hline Arginine & $85.1 \pm 4.0$ & $91.2 \pm 3.1$ & $95.7 \pm 2.4 \mathrm{a}$ & 1.05 \\
\hline Asparagine & $24.3 \pm 1.8$ & $28.4 \pm 1.4$ & $33.3 \pm 1.8$ aа & 1.17 \\
\hline Aspartic acid & $18.7 \pm 2.4$ & $9.2 \pm 1.3$ aа & $11.1 \pm 1.1 \mathrm{a}$ & 1.21 \\
\hline Cystine & $48.4 \pm 3.3$ & $60.6 \pm 1.9$ & $64.2 \pm 2.9$ & 1.06 \\
\hline Glutamic acid & $16.7 \pm 1.5$ & $12.7 \pm 1.7$ & $13.9 \pm 1.9$ & 1.09 \\
\hline Glutamine & $409.1 \pm 31.9$ & $483.1 \pm 22.8$ & $610.2 \pm 42.8 \mathrm{aa}, \mathrm{b}$ & 1.26 \\
\hline Glycine & $199.3 \pm 10.3$ & $197.0 \pm 9.5$ & $217.2 \pm 13.3$ & 1.10 \\
\hline Histidine & $57.3 \pm 4.6$ & $59.6 \pm 3.8$ & $71.0 \pm 6.3$ & 1.19 \\
\hline Isoleucine & $71.8 \pm 5.4$ & $72.6 \pm 3.3$ & $79.3 \pm 6.9$ & 1.09 \\
\hline Leucine & $103.2 \pm 11.2$ & $110.0 \pm 5.9$ & $127.0 \pm 12.6$ & 1.15 \\
\hline Lysine & $295.5 \pm 11.2$ & $254.4 \pm 13.7 \mathrm{a}$ & $279.6 \pm 12.0$ & 1.10 \\
\hline Methionine & $43.9 \pm 1.5$ & $16.7 \pm 7.3$ aа & $28.2 \pm 9.1 \mathrm{a}$ & 1.68 \\
\hline Ornithine & $42.0 \pm 3.1$ & $41.3 \pm 3.2$ & $43.1 \pm 2.5$ & 1.05 \\
\hline Phenylalanine & $55.3 \pm 5.1$ & $58.9 \pm 2.7$ & $71.5 \pm 5.2 b$ & 1.21 \\
\hline Proline & $62.4 \pm 3.7$ & $64.8 \pm 3.7$ & $68.7 \pm 3.3$ & 1.06 \\
\hline Serine & $103.0 \pm 6.7$ & $111.4 \pm 5.6$ & $121.4 \pm 4.4 \mathrm{a}$ & 1.09 \\
\hline Threonine & $131.3 \pm 5.5$ & $129.5 \pm 2.1$ & $138.2 \pm 8.8$ & 1.07 \\
\hline Tryptophan & $70.8 \pm 3.0$ & $74.8 \pm 5.3$ & $74.9 \pm 10.9$ & 1.00 \\
\hline Tyrosine & $65.9 \pm 5.8$ & $80.3 \pm 4.8$ & $101.5 \pm 6.4 \mathrm{aa}, \mathrm{b}$ & 1.26 \\
\hline Valine & $163.5 \pm 9.3$ & $157.6 \pm 6.2$ & $166.3 \pm 10.0$ & 1.06 \\
\hline Total amino acids & $2406.4 \pm 168.8$ & $2494.4 \pm 150.9$ & $2904.8 \pm 196.9 \mathrm{~b}$ & 1.16 \\
\hline Urea & $4440 \pm 135$ & $6250 \pm 153$ aа & $6973 \pm 683$ aа & 1.12 \\
\hline Fischer's ratio ${ }^{\mathrm{b}}$ & $2.82 \pm 0.11$ & $2.44 \pm 0.09 \mathrm{a}$ & $2.15 \pm 0.07 \mathrm{aa}, \mathrm{b}$ & \\
\hline
\end{tabular}

\section{Discussion}

The results of this study reveal that long-term and voluntary exercise reduced body weight gain associated with decreased visceral fat weight and hepatic TG content in female $\mathrm{A} / \mathrm{J}$ mice, despite an increase in food intake per body weight. The Ex-mice also had higher plasma levels of glutamine, Phe, and Tyr. To the best of our knowledge, this is the first report on blood amino acid concentrations in mice which consistently used a running wheel for an extended period of time, representing a constant running distance for a long period and, consequently, habitual exercise.

One possible approach to elucidate the mechanism of the effects of exercise in humans is to use an animal model in which the animal is exercising under conditions of reduced stress. In our study, compared with mice kept in a cage made of steel (Fig. 1b), those kept in a plastic cage with wood chips (Fig. 1a) had a higher body weight and showed no growth retardation at the same age (data not shown). Therefore, the long-term exercise studies were carried out in plastic cages. The adrenal glands of Ex-mice were of a similar weight to those of Se-mice and contained similar levels of vitamin $\mathrm{C}$ content, both markers of stress
[29, 30] (Table 2). These findings indicate that Ex-mice suffered little stress.

Several biological markers were analyzed, including body weight, food intake, glucose and lipid metabolism, organ weight, and blood amino acids. Rodents using a running wheel for short periods are reported to show a suppressed body weight gain and increased food intake [16, 17]. In our study, Ex-mice did show a lower body weight gain than Se-mice; however, they also showed a higher food consumption per body weight than Se-mice during the entire period, suggesting that the energy expenditure of Exmice was greater due to exercise. As shown in Table 2, Exmice had less visceral adipose tissue and a lower liver weight, consistent with results reported for rats using a running wheel for a shorter period [17]. The weight of the soleus muscle increased after long-term exercise (Table 2), which is in agreement with previous findings [31, 32]. Qualitative muscular change was also examined in this model [31, 32]. Hepatic TG content, but not cholesterol, was significantly reduced in Ex-mice compared to Se-mice (Table 2). Gollisch et al. [17] consistently showed a lower content of hepatic TG in rats using a running wheel for a shorter period, suggesting that voluntary exercise 

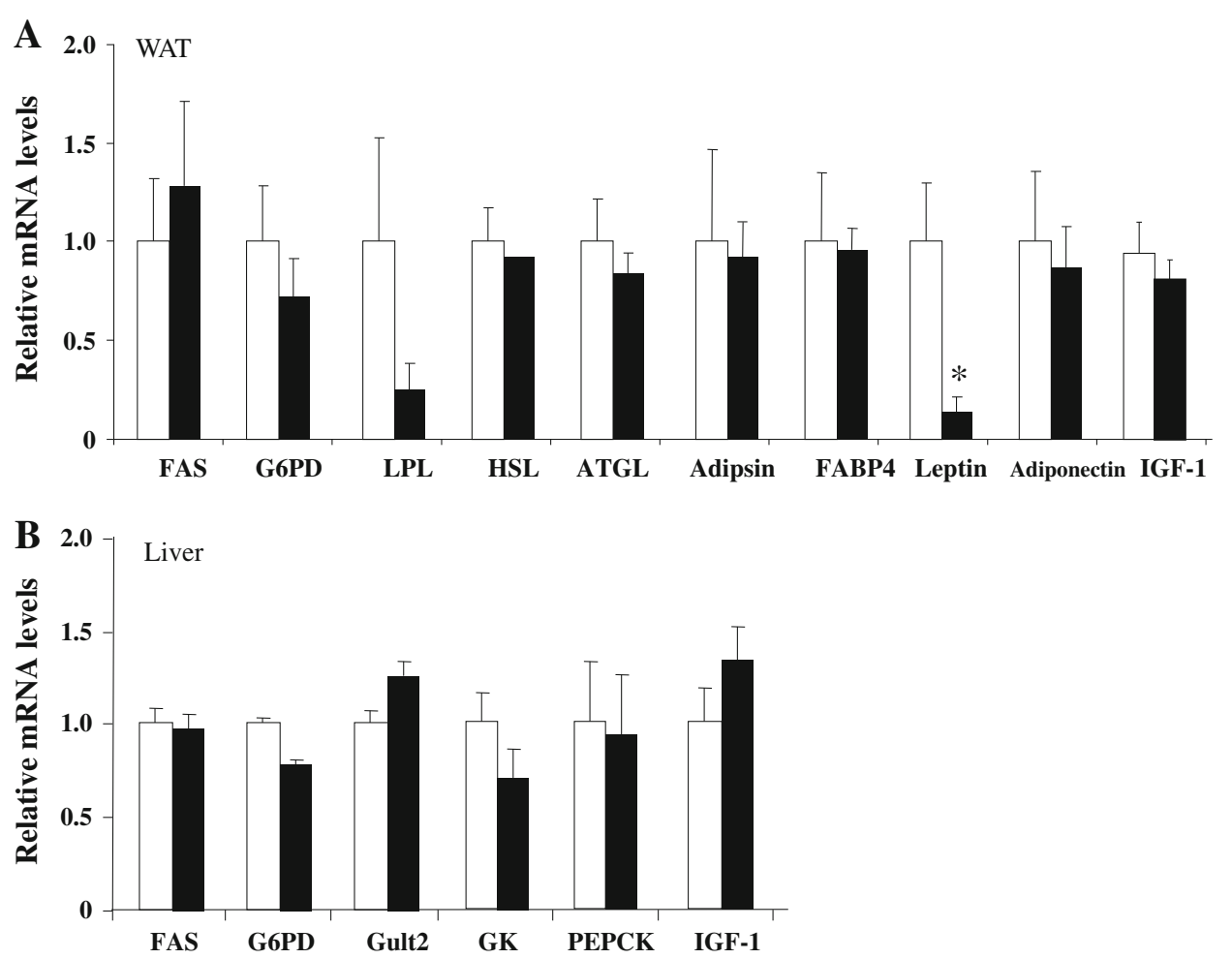

Fig. 3 Real-time PCR analysis of mRNA level in Ex-mice and Semice. a fatty acid synthase $(F A S)$, glucose-6-phosphate dehydrogenase $(G 6 P D)$, lipoprotein lipase $(L P L)$, hormone-sensitive lipase $(H S L)$, adipocyte triglyceride lipase $(A T G L)$, adipsin, fatty acidbinding protein 4 (FABP4), leptin, adiponectin, and insulin-like growth factor $1(I G F-1)$ levels in the white adipose tissue $(W A T)$ of Se-mice (open column) and Ex-mice (closed column) as determined by real-time PCR. b FAS, G6PD, glucose transporter 2 (Glut2),

suppresses the accumulation of lipids in visceral organs not only of rats, but also of mice. In our study, Ex- and Se-mice showed similar plasma glucose and insulin levels, suggesting a similar insulin sensitivity in both mice. These results are not consistent with those reported previously in which lowered glucose and insulin levels were found in mice doing voluntary exercise for 6 weeks [33]. The difference may be due to food, the duration of exercise, or the sex and strain of mice. To elucidate the significance of this difference, further experiments that includes a glucose tolerance test and glycated hemoglobin (HbA1c) measurements are required.

To understand the mechanism of reduced adipose tissue weight and hepatic TG content, we examined the expression of genes involved in lipid and glucose metabolism in adipose tissue and the liver. There were no significant differences in mRNA levels between Ex- and Se-mice, except for leptin in adipose tissue, indicating that the reduction in adipose tissue weight and hepatic TG content may not be explained by changes in the mRNA levels. However, we could not exclude the possibility these changes could be explained by transient alterations in gene glucokinase $(G K)$, phosphoenol pyruvate carboxykinase $(P E P C K)$, and IGF-1 levels in the livers of Se-mice (open column) and Ex-mice (closed column) as determined by real-time PCR. The mRNA levels relative to glyceraldehyde-3-phosphate dehydrogenase (GAPDH) were calculated with the value of Se-mice set at 1.0. There were either seven or eight samples. Results are expressed as the mean + SE. Findings were analyzed by Student's $t$ test. Statistical significance $* p<0.05$ versus Se-mice

expression during the 24 weeks of the experiment. Moreover, protein levels, rather than mRNA levels, may have altered during these 24 weeks. It is noteworthy that Exmice had significantly lower plasma IGF-1 and leptin than Se-mice. Lower plasma IGF-1 levels may not be due to a reduced synthesis of IGF-1 in the liver and WAT because there were no significant differences in mRNA levels between Ex- and Se-mice livers and WAT. Rather, lower IGF-1 may be due to translational and/or posttranslational steps, including stability in the blood. Further experiments are needed to elucidate the lower plasma IGF-1 level in Exmice. IGF-1 is a factor basically linked to muscular growth [34-36]. Exercise leads to the increased weight of skeletal muscle, but we found that the plasma IGF-1 level was lower in Ex-mice. These results indicate that the increased weight of the skeletal muscle may be caused by factors other than plasma IGF-1, such as a mechanical stimulant, namely, repeated stretching of the muscle through longterm exercise [37].

This is the first report on blood amino acids in rodents under conditions of long-term voluntary running. A previous study reported that markedly intense exercise for a 
short period resulted in decreased blood levels of glycogenic amino acids, including alanine, glutamate, and glutamine, in association with increased blood urea [20]. Reduced levels of glycogenic amino acids may correspond to enhanced gluconeogenesis and/or catabolism of the amino acids. In our study, Ex-mice showed higher alanine and glutamine levels than Se-mice, and there was no significant difference in plasma urea levels between the two groups, suggesting that exercise is unlikely to enhance gluconeogenesis or the catabolism of amino acids (Table 4) [20, 38, 39]. We also found that the levels of all plasma amino acids, with the exception of tryptophan, were higher in Ex-mice than in Se-mice, probably corresponding to increased food intake. Moreover, the higher glutamine and alanine levels (not significant, $p=0.08$ ) in Ex-mice may be explained by their enhanced synthesis and release in the hypertrophic skeletal muscles of these mice (Table 2) [40]. These explanations are supported by the correlation of the increased weight of skeletal muscle and plasma concentrations of glutamine and alanine among 6-week-old mice, Se-mice, and Ex-mice. The increased plasma Phe and Tyr levels do not mean that they are increased in the brain, causing increased dopamine; however, the decreased ratio of [BCAA]/[Phe + Tyr], a factor related to consciousness, indicates that exercise may affect brain conditions through an alteration of plasma Phe and Tyr levels [41, 42]. Habitual voluntary long-term exercise is believed to have a beneficial effect on human behavior and sleep [43, 44]. Moreover, rodents using a running wheel voluntarily for a long period showed beneficial effects on behavior [45-47]. In a preliminary experiment on novelty-induced activity by means of an open-field test, Ex-mice at 25 weeks of age (exercise for 19 weeks) showed significantly higher values during 10-min observational periods than Se-mice of the same age (Ex-mice vs. Se-mice; $361 \pm 31$ vs. $252 \pm 30$ counts, $n=8, p<0.05$ ), suggesting that Ex-mice are relatively resistant to anxiety [48, 49]. Accordingly, further studies on the relationship between behavior and amino acids in the blood are required.

We believe that the duration of voluntary exercise, 6 months, is the longest of any mouse experiments performed to date. One month for rodents may be equivalent to 2 years for humans $[18,19]$. The 6 -month duration of the exercise period for mice in our study is equivalent to more than 10 years for humans; therefore, the duration was considered to be appropriate to evaluate the effects of exercise on biological markers. However, one should be careful when extrapolating data on mice to humans due to fundamental differences between the different species.

In conclusion, body weight gain was suppressed in association with low levels of visceral adipose tissue and hepatic TG, regardless of increased food intake, indicating the importance of long-term exercise for weight control. Lower leptin and higher Phe and Tyr in plasma after long-term exercise may affect pathophysiological states related to appetite and behavior. These results also suggest the importance of having easy access to an environment, like a running wheel, in which humans can exercise voluntarily.

Acknowledgments We express our thanks to Ms Chiko Yumiba for her secretarial assistance, to Dr. Chihaya Koriyama for advice on statistical analysis, and to Mr. Yoshihiro Okada for preparing the exercise equipment for mice. We also thank Mr. George Martin (Shin Nippon Biomedical Laboratories, Ltd.) and Mr. Daniel Mrozek for copyediting the manuscript. This work was supported by Grants-inAid for Scientific Research awarded to TT and MH by the Ministry of Education, Science, Sports and Culture of Japan, by JKA through its promotion funds from KEIRIN RACE, and by Kodama Memorial Fund Medical Research.

Conflict of interest The authors declare that there are no conflicts of interest.

\section{References}

1. Laaksonen DE, Lindström J, Lakka TA, Eriksson JG, Niskanen $\mathrm{L}$, Wikström K, et al. Physical activity in the prevention of Type 2 diabetes. Diabetes. 2005;54:158-65.

2. Manini TM, Everhart JE, Patel KV, Schoeller DA, Colbert LH, Visser M, et al. Daily activity energy expenditure and mortality among older adults. JAMA. 2006;296:171-9.

3. DiPietro L. Physical activity in aging: changes in patterns and their relationship to health and function. J Gerontol A Biol Sci Med Sci. 2001;56:13-22.

4. Stallknecht B, Larsen JJ, Mikines KJ, Simonsen L, Bülow J, Galbo H. Effect of training on insulin sensitivity of glucose uptake and lipolysis in human adipose tissue. Am J Physiol Endocrinol Metab. 2000;279:E376-85.

5. Iihan N, Kamanli A, Ozmerdivenli R, Iihan N. Variable effects of exercise intensity on reduced glutathione, thiobarbituric acid reactive substance levels, and glucose concentration. Arch Med Res. 2004;35:294-300.

6. Tunstall RJ, McAinch AJ, Hargreaves M, van Loon LJC, Cameron-Smith D. Reduced plasma free fatty acid availability during exercise: effect on gene expression. Eur J Appl Physiol. 2007;99: 485-93.

7. Shi M, Wang X, Yamanaka T, Ogita F, Nakatani K, Takeuchi T. Effects of anaerobic exercise and aerobic exercise on biomarkers of oxidative stress. Environ Health Prev Med. 2007;12:202-8.

8. Ghosh S, Golbidi S, Werner I, Verchere BC, Laher I. Selecting exercise regimens and strains to modify obesity and diabetes in rodents: an overview. Clin Sci. 2010;119:57-74.

9. Kato T, Kawaguchi H, Miyoshi N, Aoyama K, Komatsu M, Horiuchi $\mathrm{M}$, et al. Effect of habitual exercise on renal carcinogenesis by ferric nitrilotriacetate. Environ Health Prev Med. 2011;16:232-8.

10. Centers for Disease Control and Prevention. Surgeon general's report on physical activity and health. JAMA. 1996;276:522.

11. Holloszy JO, Smith EK, Vining M, Adams S. Effects of voluntary exercise on longevity of rats. J Appl Physiol. 1985;59:826-31.

12. Valentinuzzi VS, Scarbrough K, Takahashi JS, Turek FW. Effects of aging on the circadian rhythm of wheel-running 
activity in C57BL/6 mice. Am J Physiol Regul Integr Comp Physiol. 1997;42:R1957-64.

13. Kariya F, Yamauchi H, Kobayashi K, Narusawa M, Nakahara Y. Effects of prolonged voluntary wheel-running on muscle structure and function in rat skeletal muscle. Eur J Appl Physiol. 2004;92:90-7.

14. Alessio HM, Hagerman AE, Nagy S, Philip B, Byrnes RN, Woodward JL, Callahan P, Wiley RL. Exercise improves biomarkers of health and stress in animals fed ad libitum. Physiol Behav. 2005;84:65-72.

15. De Bono JP, Adlam D, Paterson DJ, Channon KM. Novel quantitative phenotypes of exercise training in mouse models. Am J Physiol Regul Integr Comp Physiol. 2006;290:R926-34.

16. Droste SK, Gesing A, Ulbricht S, Müller MB, Linthorst ACE, Reul JMHM. Effects of long-term voluntary exercise on the mouse hypothalamic-pituitary-adrenocortical axis. Endocrinology. 2003;144:3012-23.

17. Gollisch KSC, Brandauer J, Jessen N, Toyoda T, Nayer A, Hirshman MF, et al. Effects of exercise training on subcutaneous and visceral adipose tissue in normal- and high-fat diet-fed rats. Am J Physiol Endocrinol Metab. 2009;297:E495-504.

18. Weindruch R, Gottesman SRS, Walford RL. Modification of agerelated immune decline in mice dietarily restricted from or after mid-adulthood. Proc Natl Acad Sci USA. 1982;79:898-902.

19. Goto S, Takahashi R, Radak Z, Sharma R. Beneficial biochemical outcomes of late-onset dietary restriction in rodents. Ann N Y Acad Sci. 2007;1100:431-41.

20. Goodrick CL. Life-span and the inheritance of longevity of inbred mice. J Gerontol. 1975;30:257-63.

21. Varney DR, Varney LA, Hemken RW, Zavos PM, Siegel MR. Onset of puberty in CD-1 mouse pups exposed prenatally through weaning to endophyte-infected tall fescue seed. Theriogenology. 1991;35:883-92.

22. Dohm GL, Beecher GR, Warren RQ, Williams RT. Influence of exercise on free amino acid concentrations in rat tissues. J Appl Physiol. 1981;50:41-4.

23. Ji LL, Miller RH, Nagle FJ, Lardy HA, Stratman FW. Amino acid metabolism during exercise in trained rats: the potential role of carnitine in the metabolic fate of branched-chain amino acids. Metabolism. 1987;36:748-52.

24. Wurtman RJ, Fernstrom JD. Control of brain monoamine synthesis by diet and plasma amino acids. Am J Clin Nutr. 1975;28:638-47.

25. Newsholme EA, Blomstrand E. Branched-chain amino acids and central fatigue. J Nutr. 2006;136:274S-6S.

26. Lightfoot JT, Turner MJ, Daves M, Vordermark A, Kleeberger SR. Genetic influence on daily wheel running activity level. Physiol Genomics. 2004;19:270-6.

27. Turner MJ, Kleeberger SR, Lightfoot JT. Influence of genetic background on daily running-wheel activity differs with aging. Physiol Genomics. 2005;22:76-85.

28. Wang Q, Li S, Jiang L, Zhou Y, Mengle S, Li W, et al. Deficiency in hepatic ATP-citrate lyase affects VLDL-triglyceride mobilization and liver fatty acid composition in mice. J Lipid Res. 2010;51:2516-26.

29. Kipp DE, Rivers JM. Uptake and release of adrenal ascorbic acid in the guinea pig after injection of ACTH. J Nutr. 1987;117: 1570-5.

30. Dhir A, Padi SSV, Naidu PS, Kulkarni. Protective effect of naproxen (non-selective COX-inhibitor) or rofecoxib (selective COX-2 inhibitor) on immobilization stress-induced behavioral and biochemical alterations in mice. Eur J Pharmacol. 2006; 535:192-8.

31. Momken I, Lechêne P, Ventura-Clapier V, Veksler V. Voluntary physical activity alterations in endothelial nitric oxide synthase knockout mice. Am J Physiol Heart Circ Physiol. 2004;287: H914-20.

32. Konhilas JP, Widegren U, Allen DL, Paul AC, Cleary A, Leinwand LA. Loaded wheel running and muscle adaptation in the mouse. Am J Physiol Heart Circ Physiol. 2005;289:H455-65.

33. Bradley RL, Jeon JY, Liu F-F, Maratos-Flier E. Voluntary exercise improves insulin sensitivity and adipose tissue inflammation in diet-induced obese mice. Am J Physiol Endocrinol Metab. 2008;295:E586-94.

34. Timtchenko D, Kratzsch J, Sauerwein H, Wegner J, Souffrant WB, Schwerin M, et al. Fat storage capacity in growth-selected and control mouse lines is associated with line-specific gene expression and plasma hormone levels. Int J Obes. 1999;23:58694.

35. Jullien D, Heydrick SJ, Gautier N, Van Obberghen E, Le Marchand-Brustel Y. Effect of IGF-1 on phosphatidylinositol 3-kinase in soleus muscle of lean and insulin-resistant obese mice. Diabetes. 1996;45:869-75.

36. Liao L, Dearth RK, Zhou S, Britton OL, Lee AV, Xu J. Liverspecific overexpression of the insulin-like growth factor-I enhances somatic growth and partially prevents the effects of growth hormone deficiency. Endocrinology. 2006;147:3877-88.

37. Goldspink G. Changes in muscle mass and phenotype and the expression of autocrine and systemic growth factors by muscle in response to stretch and overload. J Anat. 1999;194:323-34.

38. Brosnan JT. Glutamate, at the interface between amino acids and carbohydrate metabolism. J Nutr. 2000;130:988S-90S.

39. Levine S, Saltzman A. Feeding sugar overnight maintains metabolic homeostasis in rats and is preferable to overnight starvation. Lab Anim. 2000;34:301-6.

40. Garber AJ, Schwartz RJ, Seidel CL, Silvers A, Entman ML. Skeletal muscle protein and amino acid metabolism in hereditary mouse muscular dystrophy. J Biol Chem. 1980;255:8315-24.

41. Odagima $\mathrm{CH}$, Kimura Y, Adachi S, Matsuno R, Yokogoshi H. Effects of a peptide mixture with a high Fischer's ratio on serum and cerebral cortex amino acid levels and on cerebral cortex monoamine levels, compared with an amino acid mixture with a high Fischer's ratio. Biosci Biotech Biochem. 1995;59:731-4.

42. James JH. Branched chain amino acids in hepatic encephalopathy. Am J Surg. 2002;183:424-9.

43. Dishman RK. Medical psychology in exercise and sports. Med Clin North Am. 1985;69:123-43.

44. Kim K, Uchiyama M, Okawa M, Doi Y, Oida T, Minowa M, et al. Lifestyles and sleep disorders among the Japanese adult population. Psychiatry Clin Neurosci. 1999;53:269-70.

45. Binder E, Droste SK, Ohl F, Reul JMHM. Regular voluntary exercise reduces anxiety-related behaviour and impulsiveness in mice. Behav Brain Res. 2004;155:197-206.

46. Gorton LM, Vuckovic MG, Vertelkina N, Petzinger GM, Jakowec MW, Wood RI. Exercise effects on motor and affective behavior and catecholamine neurochemistry in the MPTPlesioned mouse. Behav Brain Res. 2010;213:253-62.

47. Leasure JL, Jones M. Forced and voluntary exercise differentially affect brain and behavior. Neuroscience. 2008;156:456-65.

48. Muneoka KT, Shirayama Y, Minabe Y, Takigawa M. Effects of a neurosteroid, pregnenolone, during the neonatal period on adenosine A1 receptor, dopamine metabolites in the fronto-parietal cortex and behavioral response in the open field. Brain Res. 2002; 956:332-8

49. Wada Y, Furuse T, Yamada I, Masuya H, Kushida T, Shibukawa $\mathrm{Y}$, et al. ENU mutagenesis screening for dominant behavioral mutations based on normal control data obtained in home-cage activity, open-field, and passive avoidance tests. Exp Anim. 2010;59:495-510. 